\title{
The Influence of Mobile Phone Addiction on Academic Performance Among Teenagers
}

\author{
JAMALUDDIN ABD RASHID \\ AHLAM ABDUL AZIZ \\ Universiti Teknologi MARA \\ ARIS ABDUL RAHMAN \\ Home Affair Ministry, Malaysia \\ SHAHNIL ASMAR SAAID \\ ZAIHA AHMAD \\ Universiti Teknologi MARA
}

\begin{abstract}
This study aims to identify how addiction to mobile phone usage affects academic performance. Mobile phone addiction has become a deterrent in student learning as teenagers may focus totally on their mobile phones to a point that they become dependent on them. In turn, dependence on mobile phones in their daily lives may affect teen academic performance. This study investigates mobile phone usage among teens and how it impacts their concentration on academic matters. A quantitative approach was undertaken to determine how the level of mobile phone addiction could affect their academic performance. A total of 200 respondents among secondary school students in Shah Alam were selected through purposive sampling. The questionnaire was designed in two sections, which consisted of demographic information and mobile phone usage behaviours that influence academic performance. The results show that the more the students use their mobile phones, the more it will affect their academic performance. In other words, addiction to mobile phones will affect the student's academic performance. Thus, student attention may divert away from their academics if they have high addiction to their mobile phones. As a result of this study, it has been validated that mobile phones have transformed communication and connectivity among members of the public, students in particular, and that these objects have become indispensable in this contemporary era.
\end{abstract}

Keywords: Mobile phone addiction, effect, academic performance, social media, teenagers.

\section{INTRODUCTION}

Communication has changed our daily lives due to technological advancements. The Internet and the mobile phone are two major communication evolutions that are constantly being discussed in this globalised world. Since the 1990's, the popularity of the mobile phone has sky rocketed and today, there are seven billion mobile connections worldwide with unique mobile subscriptions of over 3.5 billion (Twum, 2011). The mobile phone is a device that can make and receive calls over a radio link while we are on the move. It does so by connecting to a cellular network provided by mobile phone operators. In Malaysia, these providers are namely Maxis, DiGi, Celcom, and U Mobile, allowing access to public telephone networks. Among teenagers, mobile phone ownership has become common nowadays, as it has expanded from the basic 
functions of calling and text messaging to include applications, software and facilities that can connect users to the Internet and all forms of social media platforms (Olofinniyi et al., 2012).

In this digital era, mobile phones have the capability to download, upload, perform instant messaging, and exchange or transfer multiple media contents within the shortest time. With all these unlimited choices that highlight instant gratification, mobile phones have become an attraction, in particular to teenagers who by nature are bound to fulfil their time spending long hours on their mobile phones (Davis et al., 2012). Teenagers tend to surf the Internet and get in touch with other parties through social media such as YouTube, Facebook and Twitter. This trend is very worrying as it can affect their academic performance in school (Peterson, 2009). In Shah Alam specifically, a decrease in family interaction is evident when families are out together in public places, as each member of the family tends to be glued to their gadgets. A survey administered by The Star in January 2017 indicated a worrying inclination towards social media addiction. With reference to an article published by the Journal of Youth Studies, findings have reported that one in five teenagers "almost always" wakes up to log onto social media. It was also found that girls are more likely to be engaged with social media during the night compared to boys. The "almost always" wake up symptom may result in poor academic performance in school (Power et al., 2017).

Moreover, if a student is sleep-deprived and barely has enough rest, his/her study performance at school can be affected as it equates to lower productivity and shorter attention span. Other contemporary studies have also commented that the amount of time spent on social media has continuously increased. Statistically, teens are found to spend up to nine hours a day on social platforms, facilitated by a mobile device (Olofinniyi et al., 2012). This addiction has reached to the extreme after mobile phone companies such as Apple and Samsung introduced new and attractive applications in order to engage with audiences. Some good examples would be 360-degree photos or the Snapchat application. At present, it is believed that the more preoccupied a student is with his/her mobile phone, the higher the tendency to disregard other important aspects of life.

Due to these concerns, this study aims to address the following specific objectives:

a. To identify the level of mobile phone addiction among male and female secondary school teenagers.

b. To identify the level of mobile phone addiction according to gender and age variables.

c. To identify the relationship between mobile phone addiction and academic performance.

Hence, the research questions for this study are as listed below:

a. What is the level of mobile phone addiction among male and female secondary school teenagers?

b. What is the level of mobile phone addiction among teenagers according to gender and age variables?

c. What is the relationship between mobile phone addiction and academic performance? 
Therefore, the following hypotheses have been postulated for this study:

$\mathrm{RH} 1$ : There is a difference in mobile phone addiction among male and female secondary school teenagers.

$\mathrm{RH} 2$ : There is a difference in mobile phone addiction between gender and student age.

$\mathrm{RH} 3$ : There is a relationship between mobile phone addiction and academic performance.

\section{LITERATURE REVIEW}

A mobile phone is a gadget that can make and receive calls when connected to a network. This gadget does not require a person to stay in one place as they are able to move around within any geographical area that has cell network connectivity. A mobile phone gets interconnected to an associated network provided by a mobile phone operator, allowing access to the public telephone network. Today, the mobile phone is no longer limited to making and receiving calls. There are value-added services such as text messaging, email, online chatting, Internet access, photography and gaming. In this borderless global era, mobile communication has become part of our life regardless of religion, culture, age and community. Seong and Bo (2018) agreed that mobile phone addiction is already entrenched with Internet addiction as the symptoms and effects, either positive or negative, are similar. Plant (2001) indicated that there is no standard mobile effect although the same attitudes, rituals, responses and emotional engagements were discovered. Spending four hours on the mobile phone can be considered as addiction, though such criteria of spending seven hours was commonly categorised as a sign of addiction.

Wireless communication has emerged as one of the fastest diffusing media on the planet, fuelling an emergent "mobile youth culture" (Castells et al., 2007). Teenagers holding a phone in Shah Alam are common sights these days as parents buy them a phone to get connected. The 'mobile youth culture' addiction is normal as teenagers' phones are facilitated with applications which enable video recording, listening to music, downloading movies, playing games and accessing the Internet. Mobile phones are becoming increasingly indispensable in a student's daily life as various applications for information, education and entertainment purposes are all available through Wi-Fi. Plant (2002) indicated that frequent mobile phone usage provides teenagers and adolescents with a chance to make and develop new relationships with others as well as to assist them. Today, the growing availability of mobile phones with Internet connection and expansion in the range of services could lead to changes in a teenager's life, especially in school, and this could affect their academic performance. Having information at their fingertips can change the life of a student in terms of performing daily activities, maintaining relationships with peers and their personal welfare. Kumiko and Downes (2003) conducted a research on mobile phone addiction on students in the United States and found that students were addicted to making calls to their friends at night. This has caused poor sleeping habits and affected their academic performance.

According to Rice, Hagen and Zamanzadeh (2018), addiction to mobile use has now become an addictive public health dilemma. This phenomenon creates dangers that are linked with extreme usage and addictive behaviours. Hence, the concern must be addressed, particularly for teenagers. Today, users may become so absorbed in their phones that some unceasingly look at the phone while walking or driving. There are a lot of mobile phone addiction incidents shown on YouTube. A research conducted by ABC News in the United States exposed 
that more than 1000 people get injured while 'text walking' and this figure increases every year (Dooley, 2015). Incidents such as walking into a fall or falling down the escalator are some examples resulting from mobile phone addiction. In a more serious matter, young drivers driving a car or riding a motorcycle are often seen driving with one hand while the other hand controls their mobile phone. This highly dangerous practice may cause fatal accidents as using the mobile phone can distract attention from the road. Frequent interruptions by mobile use can disrupt face-to-face interaction, quality family time and many more.

Smart phone addiction could be considered a form of technological addiction (Derounian, 2017). Nevertheless, apart from the person-to-person disruption, uncontrollable usage of mobile phones can affect academic performance. Mobile phone addiction can be categorised as a restlessness symptom associated with attempts to frequently check the phone even though there are no notifications (Ling, 2004). Besides that, this addiction is defined as a strong desire to use the mobile phone in order to remain occupied by surfing the Internet, shopping online and playing games. Students 'interacting' with their phones out of habit can be a way to avoid communicating with parents or teachers. Some students may experience withdrawal symptoms such as insomnia, anxiety, and depression when they are without their smart phones. Rice et al. (2018) exposed that mobile phone usage relates to occupation, income and marital status of the potential users.

A step must be taken to prevent this addiction from young before children grow into teenagers. The abuse and addiction of this technology can spoil minds as the Internet can reveal many of their curiosities. Hawi and Samaha (2017) strongly agree that students must be accompanied by a form of security when using mobile phones. The risk of potential exposure to prohibited websites or even bullying can affect a child's way of thinking and even his academic performance. In this regard, other studies have also shown that gender plays a role among young users as far as mobile phone usage is concerned. Hawi and Samaha (2017) have found that older people use the mobile phone less when compared to the younger generation as the former are afraid of familiarising with new technology.

Realising the situation nowadays, children as young as three years old are already being introduced to gadgets such as smart phones and tablets. The older generation born in the 1940's or 1950's is slowly learning to use mobile phones and catching up with technology. Cutino and Nees (2017) reported that the use of new technology between boys and girls in school differs. Boys spend more time on their mobile phones as compared to girls. However, adolescents spend more time using this gadget on weekends than on casual weekdays. This shows that various factors affect mobile phone addiction. In the year 2015, the Department of Statistics Malaysia revealed that $71.1 \%$ of Malaysians aged 15 years and above use the Internet. This percentage increased by $14.1 \%$ as compared to the year 2013 .

This number increased when parents started buying their children mobile phones or the children have more than one mobile phone. Meanwhile, $97.5 \%$ individuals were using mobile phones in 2015 compared to $94.2 \%$ in 2013. This indicates that most Malaysians own a mobile phone regardless of their occupational status. Cutino and Nees (2017) indicated that phonerelated behaviour is associated with individual attributes such as age, gender and user personality. Phone-related behaviour for a person that engages in e-commerce is evidently different from a government servant. For e-commerce, a person needs to check their phone frequently as information is online. Meanwhile, for a government servant, the frequency of checking the phone 
is lesser compared to those in e-commerce businesses. A study by Yildrim, Sumuer, Adnan and Yildrim (2016) indicated that mobile phone addiction can affect student academic performance. This study also found that women spend more time on cell phones compared to men. Women spend an average of 10 hours, while men spend almost 8 hours on their mobile phone daily. In another finding, college students may also be 'victims' of online shopping as they browse the Internet to find the best deals possible.

Users of mobile phones use them in their daily life regardless of their age, gender, occupation, income and education. A conceptual framework developed by Chuma (2014) shows that demographic and lifestyle factors affect mobile phone usage. Mobile phone usage in Mauritius is different compared to Western countries, Latin America, Africa and Asia. In terms of behaviour, attitudes, value and characteristics, these factors influence mobile phone ownership (Chuma, 2014). A student in Nigeria and a student in Malaysia may have different attitudes towards mobile phones. In Malaysia, perhaps the latest trend is playing online 3D games, while in Nigeria due to technology factors, only normal games are applicable. The network of the mobile phone plays an important role in determining mobile phone addiction.

According to Jun (2019), nearly all adolescents aged 12-19 in Korea own a mobilephone and most of them (97\%) are smart phones. According to Pew Research Center, $95 \%$ of Americans own a mobile phone of some kind and in Uganda, the percentage of phone ownership is only at $65 \%$. This comparison shows that mobile phones are used differently for different kinds of people such as businessmen, students and housewives. In terms of its usage, sending texts is common and taking pictures is one of the most popular activities done using this gadget. In some countries, online mobile banking is commonly used on a mobile device and browsing e-news is a must to obtain the latest political news. However, supporting the point emphasised by Chuma (2014), a good example would be the usage of mobile phones in Royal Belum, Perak. There is no network coverage in the deep jungle so there is no value of having a smart phone in such locations.

Scholars have shown concern on factors influencing student academic performance such as learning, the influence of mobile phones, m-learning, student attendance, parent economic status, parent education, peer influence and extracurricular activities. Academic performance among students is measured through several methods such as CGPA, GPA and their test results. Many researchers around the world use GPA to measure student performance. Meanwhile, Darling et al., (2005), Galiher (2006) and Graetz (1995) stated that a student's educational success depends greatly on social standing of student's family background in society. Students who come from a low socioeconomic status are likely to have difficulties in their studies and bring trouble to school. These difficulties in studies affect their academic performance and may compromise success in life.

Walsh et al. (2010) proposed that teenagers who are too connected to their mobile phones show symptoms of behavioural addiction towards the mobile phone. The 'mobile youth culture' influencing students these days is very worrying. The trend of holding a mobile phone on one hand while the other hand performs activities such as driving, eating and walking is undesirable. According to Castells et al., (2007), wireless communication has become one of the fastest diffusing media on the planet, fuelling an emergent "mobile youth culture". Humans check their phone 34 times a day and some people experience symptoms such as insomnia and depression if their phone is not with them (Wargo et al., 2011). Most students are involved in this mobile 
phone addiction without them realising it. Chóliz (2010) pointed out that extreme mobile phone usage and dependency on it may be considered an addictive disorder.

Nowadays, students use mobile phones for many purposes. They commonly use their phones to take photos, update social media, go online shopping, chat online, for GPS navigation, to play games and use many more applications. All these activities can affect their studies as they spend more time on the mobile phone. Some students are glued to their mobile phone due to the Internet facilities. According to the Malaysia Digital Association, Malaysians are Internet addicts with growing time spent online (Malaysia Digital Association, 2016). Malaysians spend on average 5.1 hours a day on the Internet, 2.8 hours a day on social networks and $47 \%$ Malaysians access the Internet from their mobile phone. One survey revealed that $86 \%$ of responding librarians, teachers and computer coordinators believe that children do not improve their performance by using the Internet (Barber, 1997).

Based on the survey, respondents argued that information on the Internet is too unorganised and unrelated to school curriculum. The respondents stated that textbooks help students better in achieving good results. Due to excessive Internet usage on mobile phones, Young (1996) found that $58 \%$ of students are weak in study habits and frequently absent from classes. These habits can affect their grades. Many researchers acknowledge that class turnout is a main aspect in improving student performance.

A study conducted by Kim, Martinovic and Katavic (2019) found that attendance has small value, but significant effects on student learning and performance. Students who skipped class on a given date were significantly more likely to respond incorrectly to questions relating to material covered that day than students who were present. In accordance with the current pace of the globalised world, most students have their mobile phones and are glued to the phone leading to mobile phone addiction. This addiction has an impact on student academic performance. Subba et al. (2013) indicated that one third of students frequently checked their phone owing to ringxiety or phantom ring which is an indicator of mobile phone addiction, thus this affects their studies.

Personal observation in secondary school shows that most students use their phones to engage in social media such as Facebook, Instagram, Twitter and popular instant messengers such as WhatsApp. Besides that, they enjoy to record Instagram stories in their free time and to kill boredom while waiting for school transportation. The advanced technology of mobile phones has been seen to be overused by students. With this regard, control in the usage of mobile phones as well as attitude and time spent on these devices are in dire need to avoid addiction. Hence, a study has shown that adolescents between 15 and 19 years old admitted to being glued to their cell phones (Marquez et al., 2004).

For the present study, the researchers have adopted Bandura's Social Learning Theory which proposes that people learn from one another via observation, imitation and modelling. This theory has often been called a bridge between behaviourist and cognitive learning theories because it encompasses memory, attention and motivation. People learn through observing the behaviour of others, as well as attitudes and outcomes of those behaviours (Bandura, 1977). This theory addresses two aspects of this study, which are mobile phone addiction and the effect on academic performance. 
According to Social Learning Theory, three elements namely individual learners, peers and situation potentially affect the learning outcome (Bandura, 1977). This theory explains how humans develop their behaviour in terms of continuous give-and-take interaction within cognitive, behavioural and environmental influences. In the context of this study, the over-use of mobile phone interaction is considered addictive and this affects student behaviour. This behaviour causes poor academic performance.

Bandura (1977) identified Observation Learning whereby people can learn by watching other people perform the behaviour. This learning is done through observation such as 4-year old children watching a Spiderman movie and trying to imitate the character by flying. Here, Spiderman's behaviour and leadership as a hero creates observation learning. This observation can also be learned by surrounding environments and behaviour. In the famous "Bobo Doll" experiment, an adult is tasked to act aggressively towards a Bobo Doll while the child observes him. The adult was punching, kicking and throwing the doll. After the child had observed the aggressive behaviour, she was then put inside a room with the Bobo Doll. Bandura clearly indicated that the child imitated the aggressive behaviour towards the doll which she had observed earlier. In relation with this study, mobile phone addiction (behaviours) affects the learning outcome (academic performance).

Social Learning Theory teaches us that observations of other people engaging in addictive behaviour can lead to the progress of addiction. When one observes the behaviour and reactions of other people using addictive substances, one may desire to repeat what has been seen. For example, when a young child is observed coming back from school and is glued to his mobile phone playing games; his reaction is just smiling during that moment. It can be observed that mobile phone addiction is a good way of handling school stress. Social Learning Theory has been useful in explaining how people can learn new things and develop new behaviours by observing other people. It is not only external reinforcement or factors that can affect learning and behaviour, but there is also intrinsic reinforcement, which is a form of internal reward or a better feeling after performing the behaviour (Bandura, 1977).

The Modelling Process developed by Bandura (1977) indicated that not all observed behaviours could be learned effectively, nor can learning necessarily result in behavioural change. There are four steps to the analysis on determining whether social learning is a success or the opposite. If knowledge of the model is to be gained, any matter that catches one's thoughts has to be removed. If a study on mobile phone addiction of a student affects his academic performance, the feeling like "I like you" has to be ignored in order to get full attention.

The second element of the model is retention. Retention of the newly educated behaviour is necessary, while without it, learning of the behaviour would not be established. The possibility of observing the model again is high as one is not able to store information about the behaviour. Retention happens when one is successful in paying attention and retaining relevant information. This step requires demonstration via a behaviour. During this period, practice of the actions by repeatedly doing it is important for progression. Next is motivation, as behaviour is repeated in order to keep on performing it. This is where reinforcement and punishment come in. One can be rewarded if demonstrating the behaviour properly and punished if displaying it inappropriately. Social Learning Theory is relevant to this study as the academic performance of 
students in school is based on their mobile phone addiction. The addiction is a behaviour that implies the amount of time invested in looking at their mobile phone on daily basis.

In conjunction with Social Learning Theory by Bandura, findings from Bian and Leung (2015) mentioned that factors that lead to mobile phone addiction involved those who are lonely and shy. Shy and lonely people tend to depend on their mobile phone to occupy them and to only associate with those who are willing to communicate virtually. Shy and lonely people use mobile phones to escape from uncomfortable situations while in public. Their behaviour of escapism will lead to addiction to mobile phone.

The symptoms of addiction among those who constantly use mobile phones to avoid communicating with others can be seen as those who are continuously checking their phone and logging onto their social media accounts (Blachnio \& Przepiorka, 2019). David, Kim, Brickman, Ran and Curtis (2015) agreed to this statement and added that teenagers who consistently play online games were indirectly addicted to their mobile phones. In line with these findings, a theoretical framework was created based on variables suggested by the literature review.

\section{THEORETICAL FRAMEWORK}

This study adopts Bandura Social Learning Theory that theorises people learn from one another via observation, imitation and modelling. This theory has often been called a bridge between behaviourist and cognitive learning theories because it encompasses memory, attention and motivation. People learn through observing others' behaviours, attitudes, and outcomes of those behaviours. This theory answers two aspects of this study, namely mobile phone addiction and its effect on academic performance.

According to Social Learning Theory, three elements which are individual learners, peers and situation, can potentially affect the learning outcome (Bandura, 1977). This theory explains how humans develop their behaviour in terms of continuous give-and-take interaction between cognitive, behavioural and environmental influences. In the context of this study, the excessive use of mobile phone interaction is considered as an addiction, and this affects the student's behaviour, thus causing poor academic performance. Based on the literature review, this study has developed a conceptual framework as presented below.

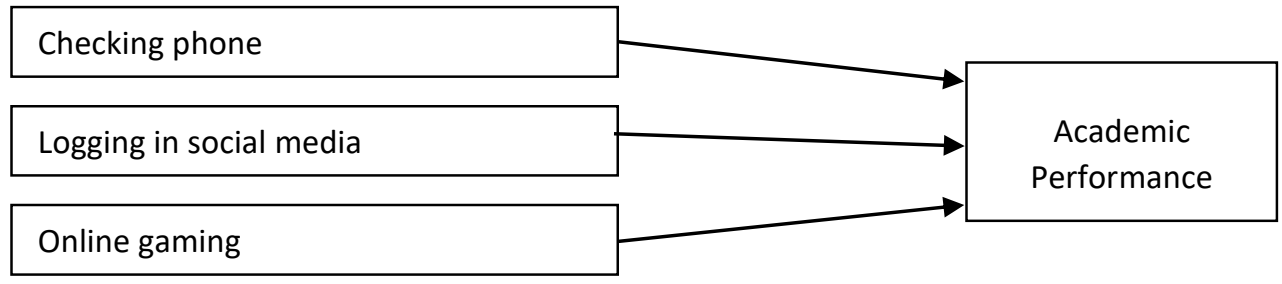

Figure 1: Framework of Relationship between Mobile Phone Addiction and Academic Performance

\section{VARIABLE AND OPERATIONAL DEFINITION}

Mobile phone addiction in this study can be considered a form of technological addiction (Lin, 2014). According to Griffiths (1996), these addictions are non-chemical behavioural addictions that involve human-machine interaction. Mobile phone addiction can cause stress, sleep disturbances and symptoms of depression which can lead to mental health outcomes (Thomée et al., 2011). Walsh et al. (2010) reiterated that teenagers are too much connected to their mobile 
phones and they show symptoms of behavioural addiction towards mobile phones. Through exploratory factor analysis, Lin et al. (2014) demonstrated that mobile phone addiction has several similar aspects to Diagnostic and Statistical Manual of Mental Disorders (DSM-5) substance-related disorders.

Four main factors that are related include compulsive behaviour, functional impairment, withdrawal and tolerance. Adolescents are highly affected by mobile phone addiction and they do not turn their phone off at night (Chóliz, 2014). There is no standard mobile effect although the same attitudes, rituals, responses and emotional engagements were discovered (Plant, 2001). The advancement of technology has also been a dominant force in affecting student's academic life (Roberts et al., 2013). Younger generations, especially students, are dependent on mobile phones and have the tendency to waste money on this device. This mobile phone dependence has a negative effect on social behaviour and education (Moisio, 2003).

This study measures the resources by asking participants questions about time spent on their mobile phone daily. Do they spend more than 3 hours daily looking at their phone or do they sleep late because of time spent on the mobile phone? These questions have been investigated. The frequency of checking phone is measured by how often they check their phone hourly, and how often they check their phone before and getting up from bed is also examined. This study also measured the frequency of logging into social media. The updating of social media status every 30 minutes and whether participants spend their free time on social media are also studied. Lastly, frequent online gaming is measured by time spent on playing games, losing sleep due to gaming and skipping classes due to gaming addiction.

Academic performance is the outcome of education to the extent to which a student, teacher or institution have achieved their educational goals (Ward et al., 1996). Academic performance among students is measured through several methods such as CGPA, GPA and their test results. Many researchers around the world use GPA to measure student performance (Darling, 2005; Galiher, 2006). Test results from the previous examination or year may also be used to measure study performance for the specific subject or year (Hijaz and Naqvi, 2006). According to the Ministry of Education Malaysia, the grading system for secondary school has the following ranking: $A=$ Excellent, $B=$ Good, $C=$ Average, $D=$ Poor and $E=$ Fail.

This study measures academic performance by asking students about their average grade in school and questions related to mobile phone addictions. The students were asked of their average grade in school. This academic performance is important for their school's overall ranking. These students need to sit for their PT3 and SPM examinations respectively according to their age category. Academic achievement is a necessary requirement if students would like to continue their studies at university. This research will investigate whether addiction to mobile phones affects academic performance negatively.

\section{METHODOLOGY}

Samples that were involved in this quantitative study were secondary school students aged 13 to 17 years old. The questionnaires were distributed to school students in the Shah Alam, Selangor vicinity. The subject of study is the influence of mobile phone addiction on the students' academic performances. 
Purposive sampling is a type of non-probability sampling in which a researcher uses his own judgments in the selection of sample members. It can sometimes be called a judgmental sample. For this research, the judgment involved in ensuring the reliability of answers were secondary school students who own mobile phones and live in Shah Alam. The researchers chose individuals that meet these criteria as the target sample due to their involvement with mobile phone usage.

This research used questionnaire as its instrument. This questionnaire is drive-structured, which is a straight to the point-oriented method, well suited for describing the whole objective of this research. The questionnaires have 20 closed-ended questions including demographic questions. In either instance, the goal of the questionnaire is to define whether there exists a relationship between mobile phone usage and academic performance among secondary school students.

For this research, questionnaires were distributed to 200 secondary school students in Shah Alam who possessed mobile phones of their own. They were asked to answer a set of questionnaire protocol that has been prepared by the Faculty of Communication and Media Studies, UiTM Shah Alam. Each respondent answered the same structured set of questions and the collected data were calculated and compared, based on its differences in answers using SPSS statistical software. At the end, the process of classifying the chart of opinions, the researchers managed to form conclusions to this research constructed from the findings.

\section{RESULTS AND DISCUSSION}

\section{a. Level of Addiction to Mobile Phones Among Teenagers}

According to Table 1, majority (64.5\%) of secondary school students are in the moderate level of addiction to mobile phones. Meanwhile, $19 \%$ of them have a low level of addiction to mobile phones. However, $16.5 \%$ of them have high level of mobile phone addiction based on the question asked to the students using a 5-Point Likert Scale, where 16 categories of addiction questions were asked. The non-addictive scale was 16 while the addictive scale is 80 . The range of the addiction scale is: 16 - 37 Low Addiction; 38 - 59 Medium Addiction and $60-80$ High Addiction. It can also be seen that all (100\%) respondents have a mobile phone of their own. The respondents use mobile phones daily, which shows secondary school students being somewhat addicted, as they tend to feel that it is necessary to use a mobile phone.

Table 1: Level of Mobile Phone Addictions among Teenagers $(n=200)$

\begin{tabular}{lll}
\hline $\begin{array}{l}\text { Addiction Level to Mobile } \\
\text { Phones }\end{array}$ & Frequency & Percentage \\
\hline High & 33 & 16.5 \\
Moderate & 129 & 64.5 \\
Low & 38 & 19 \\
Total & 200 & 100 \\
\hline
\end{tabular}

b. Level of Usage of Mobile Phones Among Teenagers According to Gender

Based on Table 2, male students used mobile phones more to communicate compared to female students. This indicates $24 \%$ of male are categorised as high users, while only $9 \%$ females were high users. 
Table 2: Level of Mobile Phone Usage Among Teenagers based on Gender $(n=200)$

\begin{tabular}{lllllll}
\hline Gender & \multicolumn{2}{l}{ Frequency } & \multicolumn{4}{c}{ Percentage } \\
& High & Moderate & Low & High & Moderate & Low \\
& & & & & & \\
\hline Male & 24 & 64 & 12 & 24 & 64 & 12 \\
Female & 9 & 65 & 26 & 9 & 65 & 26 \\
Total & 200 & & & 100 & & \\
\hline
\end{tabular}

c. Mobile Phone Usage Based on Age Group

Table 3 indicates that secondary school students aged 16-17 years old have high usage of mobile phones (64.5\%), while another $35.5 \%$ were the students from the $13-15$-year-old group. This situation happens because those from 16-17 years old rely on mobile phones not only as a communication medium, but also for gaming and leisure purposes.

Table 3: Mobile Phone Users Based on Age Groups ( $n=200)$

\begin{tabular}{lll}
\hline Age Group & Frequency & Percentage \\
\hline $13-15$ years & 71 & 35.5 \\
$16-17$ years & 129 & 64.5 \\
Total & 200 & 100 \\
\hline
\end{tabular}

d. The Relationship Between Addiction to Using Mobile Phone and Academic Performance Findings from the study show a significant positive relationship between addiction to mobile phone usage and academic performance $(r=1.00, p<0.05)$. In this situation, the more students use their mobile phones, the more it will affect their academic performance. In other words, addiction to mobile phone will affect the student's academic performance. A student's attention on academics may be diverted if they have high addiction on mobile phones.

Table 4: Relationship between mobile phone addictions with academic performance

\begin{tabular}{llll}
\hline Correlations & & Addiction & Academic \\
\hline Addiction & Pearson Correlation & 1 & $1.000^{* *}$ \\
& Sig. (2-tailed) & & .000 \\
& $\mathrm{~N}$ & 200 & 200 \\
Academic & Pearson Correlation & $1.000^{* *}$ & 1 \\
& Sig. (2-tailed) & .000 & \\
& $\mathrm{~N}$ & 200 & 200 \\
\hline$* *$ Correlation is significant at the 0.01 level (2-tailed).
\end{tabular}

The present study observes variables conceptually related to mobile phone addiction and academic performance. As mobile ownership among adolescents living in Shah Alam is highly prevalent, its effects in terms of disadvantages need to be explored. Findings from Table 5 for Research Objective 1 found that there is a significant difference in mobile phone addiction among male and female secondary school students in Shah Alam ( $t=3.847, p<0.05)$. Male and female 
students have different preferences on mobile phone usage that makes them addicted to the gadget.

Table 5: Mobile Phone Addiction Among Gender

\begin{tabular}{lccccc}
\hline \multicolumn{6}{l}{ Group Statistics } \\
\hline \multirow{4}{*}{ Addiction } & GENDER & N & Mean & Std. Deviation & Std. Error Mean \\
& MALE & 100 & 50.8400 & 13.51148 & 1.35115 \\
& FEMALE & 100 & 44.2400 & 10.57453 & 1.05745 \\
\hline
\end{tabular}

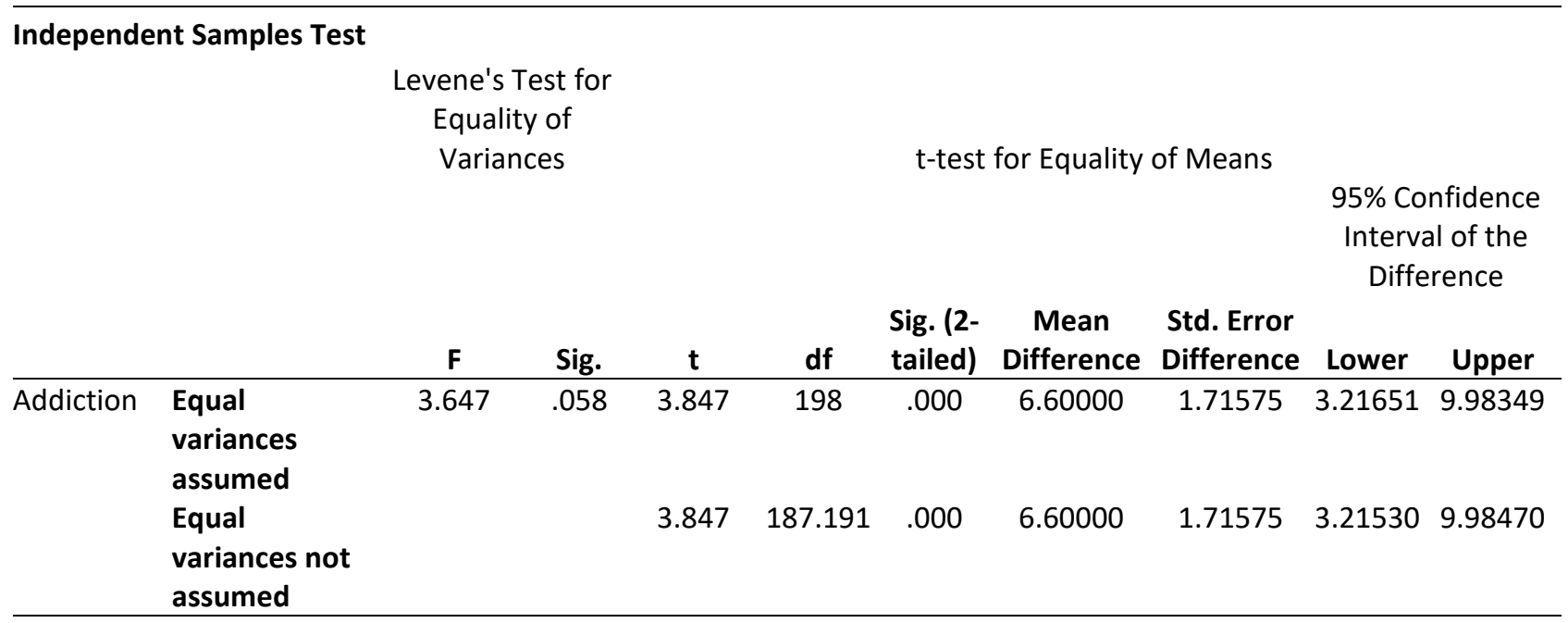

Meanwhile, results from Table 6 for Research Objective 2 found that there is no significant difference in mobile phone addiction among secondary school students from any age group $(t=1.128, p=>0.05)$. Regardless of student age, all students depended on the mobile phone in any activitiy. They have their own reasons for their dependence on mobile phones. This situation makes them addicted to their mobile phone and may not be able to live without it.

Table 6: Mobile Phone Addiction Among Age

\begin{tabular}{lccccc}
\hline Group Statistics & & & & & \\
& AGE & N & Mean & Std. Deviation & Std. Error Mean \\
\hline \multirow{2}{*}{ Addiction } & $13-15$ YEARS & 100 & 48.5400 & 14.06078 & 1.40608 \\
& $16-17$ YEARS & 100 & 46.5400 & 10.80069 & 1.08007 \\
\hline
\end{tabular}

\section{Independent Samples Test}

Levene's Test for

Equality of

Variances t-test for Equality of Means

95\% Confidence Interval of the

\begin{tabular}{|c|c|c|c|c|c|c|c|c|c|c|}
\hline & \multirow[b]{2}{*}{$\mathbf{F}$} & \multirow[b]{2}{*}{ Sig. } & \multirow[b]{2}{*}{$\mathbf{t}$} & \multirow[b]{2}{*}{ df } & \multirow{2}{*}{$\begin{array}{l}\text { Sig. (2- } \\
\text { tailed) }\end{array}$} & \multirow{2}{*}{$\begin{array}{c}\text { Mean } \\
\text { Difference }\end{array}$} & \multirow{2}{*}{$\begin{array}{l}\text { Std. Error } \\
\text { Difference }\end{array}$} & \multicolumn{2}{|c|}{ Difference } \\
\hline & & & & & & & & & Lower & Upper \\
\hline Addiction & $\begin{array}{l}\text { Equal variances } \\
\text { assumed }\end{array}$ & 8.109 & .005 & 1.128 & 198 & .261 & 2.00000 & 1.77302 & -1.49643 & 5.49643 \\
\hline & $\begin{array}{l}\text { Equal variances } \\
\text { not assumed }\end{array}$ & & & 1.128 & 185.658 & .261 & 2.00000 & 1.77302 & -1.49786 & 5.49786 \\
\hline
\end{tabular}


The survey also showed that all respondents (100\%), regardless of gender, had either Internet data on their mobile phones or access to Wi-Fi (wireless networking technology). Though making calls was the number one reason people purchased mobile phones, it is no longer so as accessibility to the Internet is regarded to be a motivating factor for mobile phone ownership. The ease of Internet access among youth is an increasingly common phenomenon, as connectivity becomes more revolutionised. Furthermore, as we move into the digital era, there exists a fear of missing out (FoMo) if one is not digitally connected, especially on social networking sites (SNS).

\section{CONCLUSION AND RECOMMENDATIONS}

This study is a unique examination of a modern-day phenomenon that is highlighting adolescents' pre-occupation with mobile phones. Mobile phones have transformed communication and connectivity among members of the public that they have become indispensable in this contemporary era. Even with all its benefits, unrestricted use of this medium can lead to detrimental effects, with more social problems arising from a lack of social skill practice, and inadequate guidelines in minimising potential threats from over-usage. Hence, this over-use will most likely lead to mobile phone addiction and negative effects on academic performance in school.

It is recommended that future studies should widen the scope of mobile phone addiction and to add questions on school grading. Furthermore, a comparative study among schools in different areas could possibly be conducted to observe the relationship between addiction to mobile phones and academic performance. Apart from that, a larger sample of the population would be useful to further strengthen the research. 


\section{BIODATA}

Jamaluddin Abd. Rashid is an Associate Professor at Faculty of Communication and Media Studies, Universiti Teknologi MARA, Shah Alam Selangor, Malaysia. His special interests are in the field of publishing management and book production. He has experience as committee member and chairman for The Technical Assessment of the Publisher Capability of Publishing and Printing School Textbooks with Malaysian Ministry of Education. Email: jamal762@uitm.edu.my

Ahlam Abdul Aziz is a Senior Lecturer at Faculty of Communication and Media Studies (UiTM). (Communication Management and Policy Programme). Her special interests are in the area of Organizational Communication, Leadership Communication and Information Technology in Organization. Email: ahlam@uitm.edu.my

Aris Abdul Rahman is an Assistant Director for the Malaysian Home Affair Ministry. He enjoys giving motivational talks to students and is actively pursuing his Master's Degree in Mass Communication and Media Studies at Universiti Teknologi MARA, Shah Alam, Selangor, Malaysia. Email: vavavom777@gmail.com

Shahnil Asmar Saaid is a Senior Lecturer at Faculty of Communication and Media Studies UiTM (Publishing Programme). Her special interests are in the field of typography, book design, publishing and media studies. She is also a member of Technical Expert in Education and Publishing, appointed by the Ministry of Science, Technology and Innovation, Malaysia. Email: asmarsaaid@uitm.edu.my

Zaiha Ahmad is a Senior Lecturer at Faculty of Communication and Media Studies, Universiti Teknologi MARA (UiTM) Shah Alam, Selangor, Malaysia. Currently, she is now a member of the Malaysian Board on Books for Young People (MBBY), and the Malaysia Editor Association. She is also a member of the Technical Experts in Publishing appointed by the Department of Standards Malaysia. Email: zaiha964@uitm.edu.my

Wan Hartini Wan Zainodin is a Senior Lecturer and presently a Deputy Dean (Academic) at Faculty of Communication and Media Studies, Universiti Teknologi MARA, Shah Alam Selangor, Malaysia. Her research interest is social media, new media and politics. She is also an active researcher as has won several National grants and consultancy projects. Email: wanhartini@uitm.edu.my 


\section{REFERENCES}

Bandura, A. (1977). Social learning theory (2nd ed.). Michigan, US: Prentice Hall.

Barber, A. (1997, March 11). Net's educational value questioned (p. 4D). USA Today.

Bian, M., \& Leung, L. (2015). Linking loneliness, shyness, smartphone addiction symptoms, and patterns of smartphone use to social capital. Social Science Computer Review, 33(1), 6179.

Blachnio, A., \& Przepiorka, A. (2019). Be aware! If you start using Facebook problematically you will feel lonely: Phubbing, loneliness, self-esteem, and Facebook intrusion. A crosssectional study. Social Science Computer Review, 37(2), 270-278.

Castells, M., Fernandez-Ardevol, M., Qiu, J. L., \& Sey, A. (2009). Mobile communication and society: A global perspective. Massachusetts: MIT Press.

Chóliz, M. (2010). Mobile phone addiction: A point of issue. Society for the Study of Addiction, 105(2), 373-374.

Chuma, W. (2014). The social meanings of mobile phones among south africa's 'digital natives': A case study. Media, Culture and Society, 36(3), 398-408).

Cutino, C. M., \& Nees, M. A. (2017). Restricting mobile phone access during homework increases attainment of study goals. Mobile Media \& Communication, 5(1), 63-79.

Darling, N., Caldwell, L. L., \& Smith, R. (2005). Participation in school-based extracurricular activities and adolescent adjustment. Journal of Leisure Research, 37(1), 51-76.

David, P., Kim, J. H., Brickman, J. S., Ran. W., \& Curtis, C. M. (2015). Mobile phone distraction while studying. New Media \& Society, 17(10), 1661-1679.

Derounian, J. G. (2017). Mobiles in class? Active learning in higher education, 1-12.

Dooley, E. (2015, August 11) Distracted walking: How 'petextrians' are endangering our streets. ABCNews.

Galiher, S. (2006). Understanding the effect of extracurricular involvement (Master's thesis). Retrieved from http://www.cscanada.org

Graetz, B. (1995). Socioeconomic status in education research and policy. Socioeconomic Status and School Education, 23-51.

Griffiths, M. (1996). Gambling on the Internet: A brief note. Journal of Gambling Studies, 12(4), 471-473.

Hawi, N. S, \& Samaha, M. (2017). The relations among social media addiction, self-esteem and life satisfaction in universty students. Social Science Computer Review, 35(5), 576-586.

Hijaz, S. T., \& Naqvi, S. R. (2006). Factors affecting students' performance: A case of private colleges in Bangladesh. Journal of sociology, 3(1), 44-45.

Jun, S. (2019). Longitudinal influences of depressive moods on problematic mobile phone use and negative school outcomes among Korean adolescents. School Psychology International, 40(3), 294-308.

Kim, S. U., Martinovic, I., \& Katavic, S. S. (2019). The use of mobile devices and applications for health information: A survey of Croatian students. Journal of Librarian and Information Science, 1-15.

Kumiko, A., \& Downes, E. J. (2003). An analysis of young peoples use of and attitudes toward cell phones. Telematics and Informatics, 20(4), 349-364. 
Lin, Y. H., Chang, L. R., Lee, Y. H., Tseng, H. W., Kuo, T. B., \& Chen, S. H. (2014). Development and validation of the smartphone addiction inventory (SPAI). PloS One, 9(6), e98312.

Ling, R. (2004, September). The mobile connection: The cell phone's impact on society. Ubiquity. Malaysian Digital Association. (2016). Malaysia Digital Landscape. Retrieved April, 25, 2017.

Márquez, E. C., Gil, V. G., Ylla-Catalá, A., Figueras, M., Balana, M., \& Naval, J. (2004). Effectiveness of an intervention to provide information to patients with hypertension as short text messages and reminders sent to their mobile phone (HTA-Alert). Atencion Primaria, 34(8), 399-405.

Moisio, R. J. (2003). Negative consequences of mobile phone consumption: Everyday irritations, anxieties and ambiguities in the experiences of Finnish mobile phone consumers. ACR North American Advances.

Olofinniyi, O. E., Fashiku, C. O., Fashiku, B. C., \& Owombo, P. T. (2012). Access to GSM and students' academic performance in Secondary School of Osun, Nigeria. Online Journal of Social Sciences Research, 1(5), 160-165.

Peterson, M. (2009). Information and communication technology affects on US college students. Cyberpsychology, 1-15.

Plant, S. (2001). On the mobile: The effects of mobile telephones on social and individual life. Motorola.

Power, S., Taylor, C., \& Horton, K. (2017). Sleepless in school? The social dimensions of young people's bedtime rest and routines. Journal of Youth Studies, 20(8), 945-958.

Rice, R. E., Hagen, I., \& Zamanzadeh, N. (2018). Media mastery: Paradoxes in college students' use of computers and mobile phones. American Behavioral Scientist, 62(9), 1229-1250.

Roberts, J. A., \& Pirog III, S. F. (2013). A preliminary investigation of materialism and impulsiveness as predictors of technological addictions among young adults. Journal of Behavioral Addictions, 2(1), 56-62.

Seong, S. C., \& Bo, K. S. (2018). Smartphone use and smartphone addiction in middle school students in Korea: Prevalance, social networking service, and game use. Health Psychology Open, 1-15.

Subba, S. H., Mandelia, C., Pathak, V., Reddy, D., Goel, A., Tayal, A., \& Nagaraj, K. (2013). Ringxiety and the mobile phone usage pattern among the students of a medical college in South India. Journal of Clinical and Diagnostic Research (JCDR), 7(2), 205.

Thomée, S., Härenstam, A., \& Hagberg, M. (2011). Mobile phone use and stress, sleep disturbances, and symptoms of depression among young adults - A prospective cohort study. BMC Public Health, 11(1), 66.

Twum, R. (2011). Influence of mobile phone technologies on sciences student's academic performance in selected Ghanian university (Master's thesis, Kenyatta University). Retrieved from http://irlibrary.ku.ac.ke/bitstream/handle/123456789/11915/Influenceof-mobile-phone-technologies-on-science-students\%27-academic-performance-inselected-Ghanaian-public-universities. pdf? sequence=1\&isAllowed=y

Walsh, S. P., White, K. M., \& Young, R. M. (2010). Needing to connect: The effect of self and others on young people's involvement with their mobile phones. Australian Journal of Psychology, 62(4), 194-203.

Ward, A., Stoker, H. W., \& Murray-Ward, M. (1996). Achievement and ability tests-Definition of the domain. Educational measurement, 2, 2-5. 
Yildrim, C., Sumuer, E., Adnan, M., \& Yildrim, S. (2016). A growing fear: Prevalence of nomophobia among turkish college students. Information Development, 32(5), 1322-1331.

Young, K. S. (1998). Internet addiction: The emergence of a new clinical disorder. Cyberpsychology \& behavior, 1(3), 237-244. 